Supporting Information

\title{
Optical Tuning of Antibacterial Activity of Photoresponsive Antibiotics
}

Xuancheng Fu, ${ }^{a, c}$ Jiamu Yu, ${ }^{b}$ Nan Dai, ${ }^{a}$ Yiming Huang, ${ }^{a}$ Fengting $L v,{ }^{a *}$ Libing Liu, ${ }^{a}$ and Shu Wang ${ }^{a, c}$

a Beijing National Laboratory for Molecular Sciences, Key Laboratory of Organic Solids, Institute of Chemistry, Chinese Academy of Sciences, Beijing, 100190, P. R. China

b The Experimental High School Attached to Beijing Normal University, Beijing 100032, P. R. China.

c College of Chemistry, University of Chinese Academy of Sciences, Beijing 100049, P. R. China

Email: lvft@iccas.ac.cn 


\section{EXPERIMENTAL SECTION}

Materials: All organic solvents were obtained from Beijing Chemical Works and used as received. 4-Aminoazobenzene and succinic anhydride were purchased from TCI. Norfloxacin was purchased from across. All chemicals were used without further purification.

Measurements: The ${ }^{1} \mathrm{H}-\mathrm{NMR}$ was taken from the Bruker Avance III $400 \mathrm{MHz} \mathrm{HD}$ spectrometer. UV-Vis absorption spectra were determined on a Thermo Scientific Evolution 201 spectrophotometer.

Synthesis of Azobenzene-carboxylic acid: 4-Aminoazobenzene (1.5 mmol) and succinic anhydride (3 mmol) were completely dissolved in super dry DMF (20 mL). The reaction was conducted $4 \mathrm{~h}$ at room temperature. Azobenzene-carboxylic acid was purified by washing with methanol in a yield of $87 \% .{ }^{1} \mathrm{H}-\mathrm{NMR}$ (400 MHz, DMSO, ppm): 12.10 (s, 1H), $9.87(\mathrm{~s}, 1 \mathrm{H}), 8.32(\mathrm{~d}, 2 \mathrm{H}), 7.93(\mathrm{~d}, 2 \mathrm{H}), 7.74(\mathrm{~d}, 2 \mathrm{H}), 7.44(\mathrm{~m}, 3 \mathrm{H}) 2.53(\mathrm{~m}, 4 \mathrm{H})$.

Synthesis of azobenzene-norfloxacin (Azo-Nor): Azobenzene-carboxylic acid (1 mmol), NEthyl-N'-(3-dimethylaminopropyl) carbodiimide hydrochloride (EDCI, $1.2 \mathrm{mmol}$ ) and Nhydroxysuccinimide (NHS, $1.2 \mathrm{mmol}$ ) were completely dissolved in super dry DMF (15 mL). Norfloxacin $(0.5 \mathrm{mmol})$ was added to the above system after $30 \mathrm{~min}$. The reaction was 
conducted for 24 hours at room temperature. Azobenzene-norfloxacin was purified by column chromatography $\left(\mathrm{CH}_{2} \mathrm{Cl}_{2} /\right.$ methanol $\left.=1 / 0.1, \mathrm{v} / \mathrm{v}\right)$ in a yield of $46 \% .{ }^{1} \mathrm{H}-\mathrm{NMR}(400$ MHz, DMSO, ppm): 13.21 (s, 1H), 9.93 (s, 1H), 9.03 (s, 1H), 8.41(m, 3H), 7.82 (d, 2H), 7.74 (d, 2H), 7.43(m, 3H), 6.03(s, 1H), $4.56(\mathrm{~m}, 2 \mathrm{H}), 3.54(\mathrm{~m}, 8 \mathrm{H}), 2.60(\mathrm{~m}, 4 \mathrm{H}), 1.42(\mathrm{~m}, 3 \mathrm{H})$.

The characterization of photochemical evaluation of Azo-Nor in DMSO: All irradiation experiments were performed with M-Ultra violet Light Source (365 nm, MUA-165) and MVisual light source (white light, MVL-210). All the concentration of Azo-Nor was set as 25 $\mu \mathrm{M}$ when testing the absorption spectra. To measure the time of reaching the balance of cis state, the absorption spectra of Azo-Nor was texted each $5 \mathrm{~s}$ upon exposed to $365 \mathrm{~nm}$ light irradiation at the intensity of $5 \mathrm{mM} / \mathrm{cm}^{2}$. By alternating the irradiation between $365 \mathrm{~nm}(20$ s, $5 \mathrm{mM} / \mathrm{cm}^{2}$ ) and white light ( $\left.1 \mathrm{~min}, 10 \mathrm{mM} / \mathrm{cm}^{2}\right)$, the photoswitching cycles was obtained. The absorbance was measured at $358 \mathrm{~nm} .{ }^{1} \mathrm{H}$ NMR was employed to study the ratio of trans and cis isomers changing in different situations. The concentration of Azo-Nor was set as $500 \mu \mathrm{M}$. Firstly, the ratio of trans and cis isomers in thermal state was texted by ${ }^{1} \mathrm{H}$ NMR. Under the irradiation of $365 \mathrm{~nm}\left(20 \mathrm{~s}, 5 \mathrm{mM} / \mathrm{cm}^{2}\right)$, the Azo-Nor transferred to UV photostationary state, then measured the ${ }^{1} \mathrm{H}$ NMR to obtained the ratio of trans and cis isomers. Upon the irradiation of white light $\left(1 \mathrm{~min}, 10 \mathrm{mM} / \mathrm{cm}^{2}\right)$, the ratio of trans and cis isomers in white light photostationary state was also obtained through ${ }^{1} \mathrm{H}$ NMR.

Bacterial strains and growth solutions: The bacterial strains were $S$. aureus (ATCC6538) 
and E. coli (Top 10). S. aureus were grown in Luria-Bertani (LB) at $37^{\circ} \mathrm{C}$. E. coli were grown in Nutrient Broth (NB) medium supplemented with required antibiotic, $10 \mu \mathrm{g} / \mathrm{ml}$ penicillin at $37^{\circ} \mathrm{C}$.

Antibacterial experiments of Azo-Nor: After the overnight growth of bacterial, S. aureus and E. coli were diluted to an $\mathrm{OD}_{600}$ of 0.1 and $100 \mu \mathrm{L}$ of solution was added to $96-$-well plate ${ }^{1}$. To test the antibacterial activity after UV irradiation, the solutions containing antibiotics were irradiated at $365 \mathrm{~nm}$ firstly for $5 \mathrm{~min}$ before adding to the cell suspension. The mixture solution of antibiotic and bacterial were grown in a microtiter plate at $37{ }^{\circ} \mathrm{C}$ under dark condition. The cell density $(650 \mathrm{~nm})$ was measured after $12 \mathrm{~h}$ with a $60 \mathrm{~s}$ shaking step before each measurement in a microplate reader. The background graphs were corrected by subtracting the $\mathrm{OD}_{650}$ at time 0.

\section{Reference}

(1) W. A. Velema, M. J. Hansen, M. M. Lerch, A. J. M. Driessen, W. Szymanshi, B. L. Feringa, Bioconjugate Chem. 2015, 26, 2592-2597. 